\title{
Use of Indomethacin in Patients with COVID-19
}

\author{
Milad Jalilian (iD) ${ }^{1}{ }^{*}$ \\ ${ }^{1}$ Student Research Committee, Kermanshah University of Medical Sciences, Kermanshah, Iran \\ "Corresponding author: Student Research Committee, Kermanshah University of Medical Sciences, Kermanshah, Iran. Tel: +98-9187931047, Email: milladj1994@gmail.com
}

Received 2021 May 31; Accepted 2021 June 16.

Keywords: Indomethacin, COVID-19, Nonsteroidal Anti-inflammatory Drugs (NSAIDs)

\section{Dear editor,}

The first case of a new severe acute respiratory syndrome was identified in East Asia at the end of 2019, which then spread all over the world. The outbreak of the syndrome was rapid and occurred in all countries. The causative agent of this emerging respiratory disease is betacoronavirus, which is why it is called severe acute respiratory syndrome coronavirus 2 or SARS-CoV2. In addition, the world health organization (WHO) has officially named the disease COVID-19. The disease primarily affects the respiratory tract, but in most cases, it leads to the dysfunction of other organs in the human body, including the gastrointestinal system, cardiovascular system, and central nervous system. Moreover, patients with severe COVID-19 experience cytokine storm syndrome, which is considered the leading cause of death $(1,2)$. Since the outbreak of the disease, different researchers have introduced proper solutions to control the disease, including different drugs, most of which were used to treat other diseases (3). Most of these drugs prevent the exacerbation of the disease and reduce its symptoms. In fact, the main objective of these medications is to prevent the deterioration in the condition of patients. In this regard, nonsteroidal anti-inflammatory drugs (NSAIDs) are proposed, which are widely used across the world to control acute and chronic pain in patients suffering from diseases such as arthritis rheumatoid and osteoarthritis (4). One of the most recognized NSAIDs is indomethacin. In general, indomethacin is an anti-inflammatory and anti-fever drug that affects cyclooxygenase-1 and cyclooxygenase-2 enzymes (COX-1 and COX-2) (5). Indomethacin was first used in the 1960 s to control rheumatoid pain (6). Due to its effects, this medication is recommended by different physicians worldwide to control COVID-19 symptoms in patients.

In the present study, we evaluated the possible effect of indomethacin. Different studies have assessed the effect of indomethacin as an antiviral drug. In a study, indomethacin was suggested as an effective drug to improve the condition of COVID-19 patients. $75 \mathrm{mg}$ of indomethacin extended-release capsules, twice a day, is considered as the most effective dose of the drug, which can improve the patients' conditions in three days. Meanwhile, $50 \mathrm{mg}$ of the drug, three times a day is also useful (3). The study conducted by Kiani revealed that the combination of ketotifen with indomethacin reduced viral yield, in a way that 79,83 , and $93 \%$ virus inhibition occurred with 25,50 , and $100 \mathrm{uM}$ doses of the foregoing combination, respectively. Moreover, indomethacin alone could be used to inhibit the virus and stop the virus replication process up to $50 \%$ (7). In fact, taking indomethacin for one day can inhibit $63 \%$ of the viral load (3). In general, indomethacin can inhibit virus replication and combat inflammation caused by the virus and immune system. The study conducted by Gomeni revealed that indomethacin inhibits the virus replication process and stops the virus before pathogenesis (3). Kiani also mentioned the role of indomethacin to stop virus replication. In other words, indomethacin has a direct effect on coronavirus binding or entry into host cells (7).

The results of Amici's study revealed that indomethacin prevents CCOV and SARS activity by affecting replication in dog cells. However, indomethacin did not affect coronavirus binding or entry into host cells but could block viral RNA synthesis. It seems that the antiviral effect of indomethacin is due to inhibiting cyclooxygenase. Furthermore, the antiviral effect of indomethacin can be attributed to the activation of protein kinase $-\mathrm{R}$ (8). Other studies have introduced the renin-angiotensin system (RAS) inhibitory effect as one of the possible mechanisms of indomethacin activity against COVID-19 (9). This mechanism can be the cause of the antiviral effect of

Copyright (c) 2021, Journal of Kermanshah University of Medical Sciences. This is an open-access article distributed under the terms of the Creative Commons Attribution-NonCommercial 4.0 International License (http://creativecommons.org/licenses/by-nc/4.0/) which permits copy and redistribute the material just in noncommercial usages, provided the original work is properly cited. 
NSAIDs, especially indomethacin, against COVID-19. Another interesting benefit of indomethacin is its ability to modulate cytokine production and reduce interleukin- 6 generation. This drug prevents inflammatory reactions and cytokine storms. In addition, indomethacin could alleviate some of the COVID-19 symptoms, particularly the dry cough, which is probably due to the inhibition of ACE (10). The anti-inflammatory and anti-cytokine storm effects of indomethacin in combination with its antiviral impact on SARS 1 and CCoV show how indomethacin can help a COVID-19 patient to fight against the disease.

Having reviewed the related literature, we can conclude that indomethacin can appropriately decrease the severity and symptoms of the disease, reduce hospitalization, and foster recovery of patients. Indomethacin could be used for the treatment of COVID-19 for two reasons, which are its anti-inflammatory and anti-cytokine storm effect and its inhibitory effect on the virus replication process.

\section{Footnotes}

Authors' Contribution: Milad Jalilian is the only author of the article and the study was solely carried out by the author.

Conflict of Interests: There was no conflict of interest. Funding/Support: It was not declared by the author.

\section{References}

1. Azevedo RB, Botelho BG, Hollanda JVG, Ferreira LVL, Junqueira de Andrade LZ, Oei S, et al. Covid-19 and the cardiovascular system: A com- prehensive review. J Hum Hypertens. 2021;35(1):4-11. doi: 10.1038/s41371020-0387-4. [PubMed: 32719447]. [PubMed Central: PMC7384729].

2. Kaur S, Bansal R, Kollimuttathuillam S, Gowda AM, Singh B, Mehta D, et al. The looming storm: Blood and cytokines in COVID-19. Blood Rev. 2021;46:100743. doi: 10.1016/j.blre.2020.100743. [PubMed: 32829962]. [PubMed Central: PMC7431319].

3. Gomeni R, Xu T, Gao X, Bressolle-Gomeni F. Model based approach for estimating the dosage regimen of indomethacin a potential antiviral treatment of patients infected with SARS CoV-2. J Phar macokinet Pharmacodyn. 2020;47(3):189-98. doi: 10.1007/s10928-02009690-4. [PubMed: 32435882]. [PubMed Central: PMC7237801].

4. Krasselt M, Baerwald C. Celecoxib for the treatment of musculoskeletal arthritis. Expert Opin Pharmacother. 2019;20(14):1689-702. doi: 10.1080/14656566.2019.1645123. [PubMed: 31339385].

5. Chennamaneni S, Zhong B, Lama R, Su B. COX inhibitors Indomethacin and Sulindac derivatives as antiproliferative agents: synthesis, biological evaluation, and mechanism investigation. Eur J Med Chem. 2012;56:17-29. doi: 10.1016/j.ejmech.2012.08.005. [PubMed: 22940705].

6. Huskisson EC, Taylor RT, Burston D, Chuter PJ, Hart FD. Evening indomethacin in the treatment of rheumatoid arthritis. Ann Rheum Dis. 1970;29(4):393-6. doi: 10.1136/ard.29.4.393. [PubMed: 4916769]. [PubMed Central: PMC1031323].

7. Kiani P, Scholey A, Dahl TA, McMann L, Iversen JM, Verster JC. In vitro assessment of the antiviral activity of ketotifen, indomethacin and naproxen, alone and in combination, against SARS-CoV-2. Viruses. 2021;13(4). doi:10.3390/v13040558. [PubMed:33810356]. [PubMed Central: PMC8065848].

8. Amici C, La Frazia S, Brunelli C, Balsamo M, Angelini M, Santoro MG Inhibition of viral protein translation by indomethacin in vesicular stomatitis virus infection: Role of eIF2alpha kinase PKR. Cell Microbiol. 2015;17(9):1391-404. doi: 10.1111/cmi.12446. [PubMed: 25856684]. [PubMed Central: PMC7162271].

9. Oh KK, Adnan M, Cho DH. SARS-CoV-2 intervened by NSAIDs: A network pharmacology approach to decipher signaling pathway and interactive genes. Research Square. 2020;PrePrint. doi: 10.21203/rs.3.rs111615/v1.

10. Steiner JF. Weight reduction and sodium reduction caused small decreases in blood pressure in adults with high-normal blood pressure. ACP Journal Club. 1992;117(1):2. doi: 10.7326/acpjc-1992-117-1-002. 